\title{
Anionic Polymerization of Isoprene. I. Polymerization of Isoprene by Oligomeric Dilithium Initiator
}

\author{
Satoshi Ayano and Seizo Yabe \\ Polymer Research Laboratories, Japan Gas Chemical Co. Ltd., \\ Hiratsuka, Kanagawa, Japan. \\ (Received August 5, 1970)
}

\begin{abstract}
The preparation of homogeneous initiators having active sites at both ends and the polymerization of isoprene by oligomeric dilithium initiator in benzene were studied.

Metallic lithium was allowed to react with naphthalene in diethyl ether. We removed insoluble residues from reaction products, added styrene or isoprene, and then completely removed diethyl ether and added benzene. We found that by doing so, the obtained solutions were substantially free from ether and were readily soluble in nonpolar solvents to form a homogeneous solution of an initiator.

The relationship between the number-average molecular weight and the ratio of monomer concentration to initiator concentration in the reaction of oligomerization suggested that the propagation species would be at both polymer ends.

The polymerization of isoprene by oligomeric dilithium initiator in benzene was homogeneous and had no induction period.

It was found that the increase in yield was linear with time and the yield and the monomer concentration had no effect on the microstructure of poloisoprene.

The molecular weight distribution of the oligomeric initiator and polymer was very narrow.

A test piece prepared from the polymer obtained in this reaction by the standard rubber compound method had good mechanical properties.

KEY WORDS Isoprene / Oligomeric Dilithium / Lithium Metal /

Naphthalene / Microstruture / Molecular Weight Distribution /
\end{abstract}

Table I. Polymerization of isoprene by lithium initiator in hydrocarbon

\begin{tabular}{|c|c|c|c|c|c|}
\hline \multicolumn{2}{|r|}{ Initiator } & \multirow[t]{2}{*}{ System } & \multirow[t]{2}{*}{ Solvent } & \multirow{2}{*}{$\begin{array}{l}\text { cis }-1,4 \\
\text { content } \%\end{array}$} & \multirow[t]{2}{*}{ Literature } \\
\hline No. & Type & & & & \\
\hline $1 .^{\mathrm{a}}$ & $\begin{array}{l}\mathrm{Li}-(\mathbf{M})_{n}-\mathrm{Li} \\
\mathbf{M}: \mathrm{St}, \mathrm{Ip}\end{array}$ & Homo. & $\begin{array}{l}\text { Benzene } \\
n \text {-Hexane }\end{array}$ & $90-93$ & Patent pending (this work) \\
\hline 2. & $\mathrm{Li}$ & Hetero. & Pentane & $<93$ & D. J. Kelly and A. V. Tovolsky, ${ }^{1}$ \\
\hline 3. & $\begin{array}{l}\text { Ar-Li } \\
\text { Ar:Naph. }\end{array}$ & Hetero. & $\begin{array}{l}\text { Pentane } \\
\text { Benzene }\end{array}$ & $<90$ & $\begin{array}{l}\text { S. Bywater and J. Worsford, }{ }^{2} \\
\text { M. Amagasa, et al., }{ }^{3}\end{array}$ \\
\hline 4. & $\begin{array}{l}\mathrm{Li}-\left(\mathrm{CH}_{2}\right)_{n}-\mathrm{Li} \\
n: 1-6,10,18\end{array}$ & Hetero. & $\begin{array}{l}\text { Pentane } \\
\text { Benzene }\end{array}$ & $90-93$ & $\begin{array}{l}\text { J. Furukawa, et al. }{ }^{4} \\
\text { U.S. Patent } 3208988(1965)^{12} \text {; Japanese Patent S38- } \\
7242 \text { (1963). }\end{array}$ \\
\hline 5. & $\begin{array}{l}\mathrm{Li}-(\mathrm{Ar})-\mathrm{Li} \\
\text { Ar:Phenyl }\end{array}$ & Hetero. & $\begin{array}{l}\text { Pentane } \\
\text { Benzene }\end{array}$ & $90-92$ & $\begin{array}{l}\text { Japanese Patent S41-9 } 443 \text { (1966); Japanese Patent } \\
\text { S40-15 } 830 \text { (1965). }\end{array}$ \\
\hline 6. & $\begin{array}{l}\mathrm{Ar}-\mathrm{Li} \\
\mathrm{Li}-(\mathrm{M})_{n}-\mathrm{Li}\end{array}$ & Hetero. & $\begin{array}{l}\text { Pentane } \\
\text { Benzene }\end{array}$ & $<90$ & $\begin{array}{l}\text { U.S. Patent } 3157 \text { 604; U.S. Patent } 3287 \text { 333; } \\
\text { Japanese Patent S38-27 592 (1963). }\end{array}$ \\
\hline 7. & $\begin{array}{l}\mathrm{Bu}-(\mathbf{M})_{n}-\mathbf{L i} \\
\mathbf{M}: \mathrm{Ip}\end{array}$ & Homo. & $n$-Heptane & $<92$ & $\begin{array}{l}\text { M. Morton and L. J. Fetters }{ }^{5} \text {, } \\
\text { D. Margerison and D. M. Bishon, et al., }{ }^{6}\end{array}$ \\
\hline 8. & $\begin{array}{l}\mathrm{R}-\mathrm{Li} \\
\mathrm{R}: n-, \text { sec-, ter- }\end{array}$ & Homo. & n-Heptane & $90-93$ & $\begin{array}{l}\text { A. Gugot and J. Vialle } \\
\text { H. Morita and A. V. Tovolsky, }{ }^{8} \\
\text { J. E. L. Roovers and S. Bywater }{ }^{9}\end{array}$ \\
\hline
\end{tabular}

a This work. 
It is known that by using lithium initiators, polyisoprene containing more than $90 \% \mathrm{cis}-1,4$ structural units can be obtained. ${ }^{10}$

In order to prepare polyisoprene having a high cis-1, 4 content and narrow molecular weight distribution, homogeneous initiators active at both ends were prepared. By using the initiator it is easy to control the molecular weight distribution of polyisoprene and to obtain A-B-A-type block copolymers (in which $\mathbf{A}$ is vinylpolymer and $\mathbf{B}$ is polyisoprene).

Buthyllithium is a homogeneous initiator but it is active only one end. ${ }^{11}$

Tetramethylenedilithium $^{12}$ and phenylenedilithium ${ }^{13}$ are bifunctional but heterogeneous.

The initiator, which was prepared by mixing naphthalene, lithium, and isoprene or styrene, was also heterogeneous because the naphthalene -lithium complex is insoluble in nonpolar solvents.

Table I shows several previously published investigations on lithium initiators.

\section{EXPERIMENTAL}

The procedures, including purification of materials and preparation of initiators and polymers, was carried out in a high vacuum system or in a stream of pure argon.

\section{Materials}

Naphthalene (Naph). Naph was purified by sublimation.

Isoprene (Ip). Ip (IFP polymerization grade) was fractionally distilled under argon. Then it was distilled in a vacuum system on to oligostyryldilithium and allowed to stand for $10 \mathrm{~min}$ at room temperature. The purified Ip was distilled in vacuo into a reaction vessel.

Styrene (St). St was fractionally distilled in argon at reduced pressure. Then after degassing, it was distilled in a vacuum system on to oligostyryldilithium and allowed to stand for 10 minutes at $-20^{\circ} \mathrm{C}$. It was then distilled in vacuo into a reaction vessel.

Diethyl Ether (DE). DE was purified by washing with a 10-\% aqueous solution of sodium bisulfite for 1 hour; with an aqueous solution of saturated sodium chloride containing 10-\% sodium hydroxide; with an aqueous solution saturated with sodium chloride containing a little sulfuric acid, and then with an aqueous solution of saturated sodium chloride before drying and distilling twice over calcium chloride.

It was then distilled on to naphthalene and metallic sodium to form a violet solution, from which the ether was distilled in a vacuum system just before use.

Benzene. Benzene was purified by washing with concentrated sulfuric acid and then water, drying, and distilling twice over sodium wire in vacuo. It was transferred in vacuo to a flask containing oligostyryldilithium and distilled into a reaction vessel just before use.

Lithium (Li). Merck A. G.

\section{Preparation of Initiator Solution}

In a sufficiently dried egg plant-shaped flask equipped with a magnetic stirrer and stop cock, $0.01 \mathrm{~mol}$ of Naph and $0.5 \mathrm{~mol}$ of metallic $\mathrm{Li}$ were placed in vacuo and stirred at $20^{\circ} \mathrm{C}$ for $40 \mathrm{hr}$. After the unreacted metallic $\mathrm{Li}$ was filtered off, $0.03 \mathrm{~mol}$ of purified St monomer was added in vacuo and stirred for $2 \mathrm{hr}$ at $20^{\circ} \mathrm{C}$ and $3 \mathrm{hr}$ at $25^{\circ} \mathrm{C}$.

The ether was subsequently removed by vacuum distillation. The distillation was repeated three times by the addition of benzene in to replace residual ether completely and $100 \mathrm{ml}$ of benzene was added to obtain an initiator solution.

The oligostyryldilithium concentration was determined by titration with an aqueous solution of hydrochloric acid. The amount of DE remaining was determined by gas chromatography.

\section{Polymerization of Isoprene}

A $150-\mathrm{m} l$ reactor, equipped with ampoule containining Ip monomer, solvents and an ampoule containing the initiator solution, was fully evacuated and dried by heating with a hand torch in vacuo. Then the solvents, purified and degassed in vacuo, were added in the reactor. Firstly through a breaker the initiator solution was placed in the reactor, and then a breaker seal was broken and the Ip solution added and the mixture stirred at ambient temperature. The polymerization was allowed to proceed for about $4 \mathrm{hr}$. The reactor was then opened and the product poured into an excess 


\section{S. Ayano and S. Yabe}

of methanol containing about $1 \%$ of $\beta$-phenylamine antioxidant, based on the amount of polymer. The precipitated polymer was separated by filtration and dried at $50^{\circ} \mathrm{C}$ in vacuo for $48 \mathrm{hr}$.

\section{Analysis}

The microstructure of polyisoprene was determined in accordance with the infrared method. ${ }^{14}$ The molecular weight distribution was determined by gel-permeation chromatography using a Waters model GPC-200 in tetrahydrofuran (THF) solution. The number-average molecular weight $\left(\bar{M}_{n}\right)$ was determined with a Hewlet Packard 502 membrane osmometer and a Mechrolab Inc. 301-A vapour pressure osmometer in toluene solution at $30^{\circ} \mathrm{C}$. A test piece was prepared by the standard rubber compound method and its mechanical properties were determined by a Toyo Sokki Tensilon.

\section{RESULTS AND DISCUSSION}

\section{The Preparation of Initiator}

It is known that in the polymerization of styrene initiated with Naph-sodium in THF the polymer grows at both ends. ${ }^{15}$

From this result we consider that the polymerization of St with Naph- $\mathrm{Li}$ in DE also takes place at both ends of the polymer.

Figure 1 shows that the relationship between the degree of polymerization $(\bar{P})$ and the ratio of monomer concentration to Naph- $\mathrm{Li}$ concentration in $\mathrm{DE}$ at $25^{\circ} \mathrm{C}$.

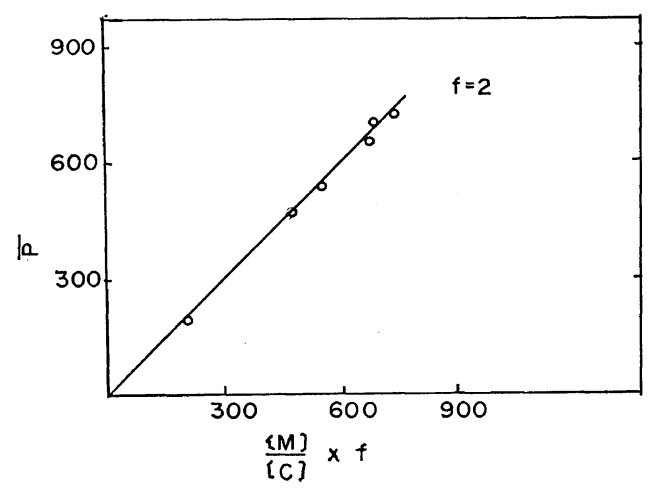

Figure 1. Relationship between $\bar{P}$ and $\mathrm{M} / \mathrm{C} \times f$. Polymerization of isoprene or styrene by naphthalenelithium in diethyl ether at $25^{\circ} \mathrm{C}$.
$\bar{P}$ is the degree of polymerization which was determined by a membrane osmometer, and 2 $\mathrm{M} / \mathrm{C}(f=2)$ is the calculated value in the case where the propagation species are at both ends of the polymer. In Figure 1 both values are in close agreement. For this reason we believe polymerization took place at both ends of the polymer.

In order to obtain $c i s-1,4$ polyisoprene $\mathrm{DE}$ must be replaced with a nonpolar solvent such as benzene, hexane or $n$-heptane.

In the preparation of oligolithium initiator, the unreactive $\mathrm{Naph}-\mathrm{Li}$ complex remains in the reaction mixture when $\mathrm{M} / \mathrm{C}$ is very small, so the solution of the initiator becomes heterogeneous in nonpolar solvents.

We found that the ratio $(\mathrm{M} / \mathrm{C})$ equal to 5 was best. If the solution of the initiator is heterogeneous, it is difficult to control the molecular weight of the resulting polymer and it has a disadvantage in the preparation of IpSt copolymers.

In order to obtain a polyisoprene having a high cis-1,4 structural unit content, the amount of ether remaining should be less than $0.01 \%$ by weight, when it is made into a solution of a nonpolar solvent having a lithium concentration of $1 \mathrm{~mol}$ per liter.

Under the following conditions we determined the amount of DE.

$$
\begin{aligned}
& \text { Apparatus .... Shimazu GC-1C } \\
& \text { Column .... Dioctyl sebacate } \\
& 2 \mathrm{~mm} \times 6 \mathrm{~m} \\
& \text { Column temp .... } 90^{\circ} \mathrm{C} \\
& \text { Sample charge temp. } 145^{\circ} \mathrm{C} \\
& \text { Detector temp . . } 150^{\circ} \mathrm{C} \\
& \text { Carrier flow rate. . } 45 \mathrm{~m} l / \mathrm{min}(\mathrm{He})
\end{aligned}
$$

\section{The Polymerization of Isoprene}

The polymerization of Ip was performed with oligostyryldilithium initiator in a homogeneous phase. The results are shown in Figure 2.

It was found that no induction period was seen in this reaction system and the conversion increased linearly with time.

From these results we assume the initiation of Ip with oligostyryldilithium proceeds rapid$1 y$.

Figure 3 shows the relationship between the $\bar{M}_{n}$ and conversion. The $\bar{M}_{n}$ increases with 
Anionic Polymerization of Isoprene. I.

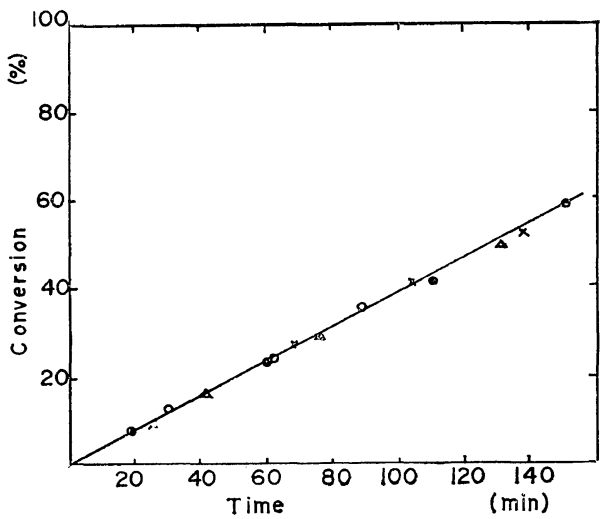

Figure 2. Time-Conversion curve of isoprene polymerization by oligostyryldilithium in benzene at $25^{\circ} \mathrm{C}: \times,[\mathrm{C}], 0.66 \times 10^{-2} \mathrm{~mol} / l,[\mathrm{M}], 0.725 \mathrm{~mol} / l$; $\mathrm{O},[\mathrm{C}], 0.65 \times 10^{-2} \mathrm{~mol} / l,[\mathrm{M}], 1.395 \mathrm{~mol} / l ; \triangle,[\mathrm{C}]$, $0.59 \times 10^{-2} \mathrm{~mol} / l,[\mathrm{M}], 3.600 \mathrm{~mol} / l ; \bullet,[\mathrm{C}], 0.72 \times$ $10^{-2} \mathrm{~mol} / l,[\mathrm{M}], 5.360 \mathrm{~mol} / l$.

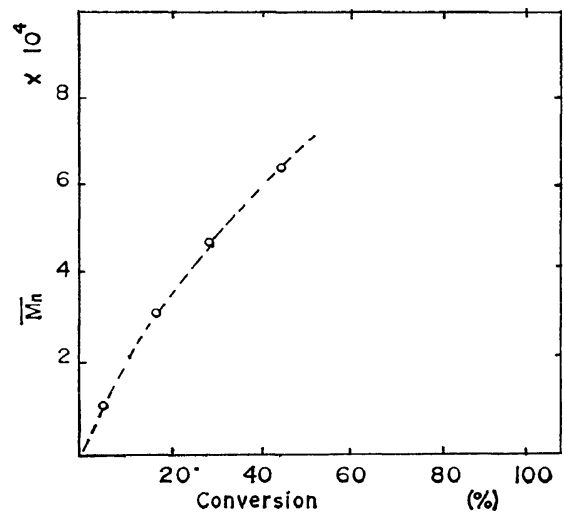

Figure 3. Relationship between $\bar{M}_{n}$ and conversion. Polymerization of isoprene by oligostyryldilithium in benzene at $25^{\circ} \mathrm{C}$.

conversion, but it is larger than the calculated values. The reason is not clear.

Figure 4 shows the effect of conversion on the microstructure of oligoisoprenyldilithiuminitiated polyisoprene. The conversion has no effect on the microstructure of polyisoprene. It is favorable because it is possible to produce a low-molecular weight polyisoprene which is rich in $c i s-1,4$ structural unit content.

Figure 5 shows the effect of initiator and monomer concentrations on the microstructure of polyisoprene.

In Figure 5 the ratio of monomer concentra-

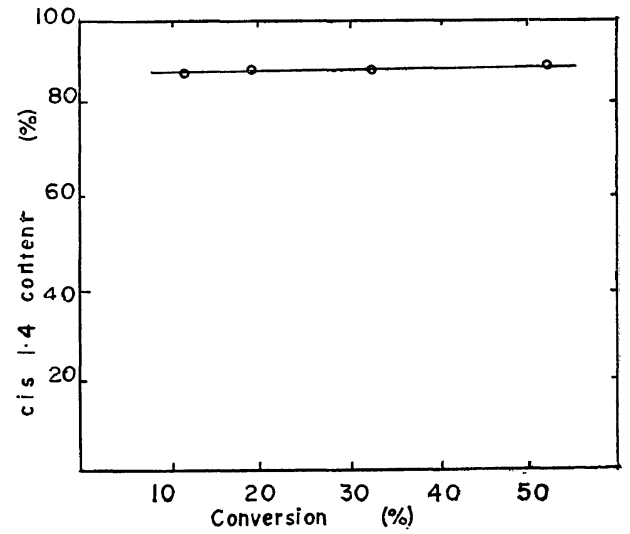

Figure 4. Effect of conversion on the microstructure of oligoisoprenyldilithium-initiated polyisoprene in benzene at $40^{\circ} \mathrm{C}:[\mathrm{C}], 4.72 \times 10^{-3} \mathrm{~mol} / l$; $[\mathrm{M}], 3.52 \mathrm{~mol} / \mathrm{l}$.

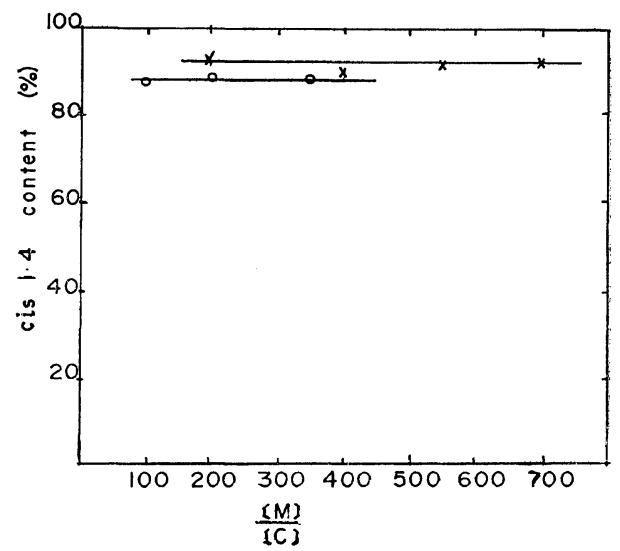

Figure 5. Effect of initiator and monomer concentration on the microstructure of polyisoprene in benzene at $25^{\circ} \mathrm{C}: \times$, solvent substituted IV; $O$, solvent substituted III.

Table II. Recipe ${ }^{a}$

\begin{tabular}{lr}
\hline Polyisoprene & 100 parts by weight \\
Zinc stearate & 3 parts by weight \\
Sulfur & 2 parts by weight \\
TMT $^{\mathrm{b}}$ (vulcanizing accelerator) & 1 part by weight \\
BHT $^{\mathrm{c}}$ (antioxidant) & 1 part by weight \\
Stearic acid & 1 part by weight
\end{tabular}

a Vulcanizing conditions, $150^{\circ} \mathrm{C} ; 8 \mathrm{~min} ; 150 \mathrm{~kg} / \mathrm{cm}^{2} \mathrm{G}$.

b TMT, tetramethyl thuiram disulfide.

c BHT, 2, 6-di-tert-butylphenol. 


\section{S. AYANO and S. YABE}

Table III. Characterization of polyisoprene and mechanical properties of vulcanized polyisoprene

\begin{tabular}{lccc}
\multicolumn{1}{c}{ Expt no. } & 110 & 123 & Califlex 305 (Shell Chemical Company) \\
\hline $\bar{M}_{n}$ & $3.85 \times 10^{5}$ & $3.90 \times 10^{5}$ & $6.00 \times 10^{5}$ \\
cis- 1,4 content, $\%$ & 90.5 & 92.5 & 92.0 \\
$300 \%$ Mod., $\mathrm{kg} / \mathrm{cm}^{2}$ & 9.2 & 12.0 & 9.6 \\
$600 \%$ Mod., $\mathrm{kg} / \mathrm{cm}^{2}$ & 18.0 & 22.4 & 20.7 \\
Elongation, $\%$ & 1100 & $1000^{\mathrm{a}}$ & $975^{\mathrm{a}}$ \\
Tensile strength, $\mathrm{kg} / \mathrm{cm}^{2}$ & 88.3 & 110.0 & 118.0 \\
Hardness (shore A) & 27 & 27 & 26 \\
\hline
\end{tabular}

a Did not break.

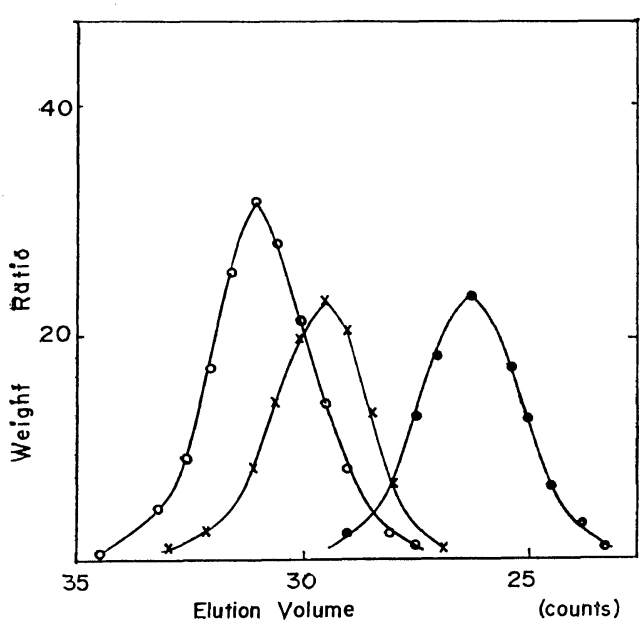

Figure 6. GPC elution pattern of standard polymer and samples: $\bigcirc$, initiator (oligostyrene), $\bar{M}_{n}$, 2300; ๑, polyisoprene, $\bar{M}_{n}, 3.1 \times 10^{4} ; \times$, standard polystyrene $\bar{M}_{n}, 1.0 \times 10^{4}, \bar{M}_{w} / \bar{M}_{n}, 1.06$.

tion to initiator concentration has no effect on the microstructure of polyisoprene.

In the polymerization of Ip initiated with $n$ BuLi at a high initiator concentration cis-1,4 content is low. Figure 6 shows the gel-permeation chromatography elution patterns of standard polystyrene, initiator, and polyisoprene. From these patterns we found that both the initiator and polyisoprene have a very sharp molecular weight distribution.

By using the polymer obtained by this reaction, a test piece was prepared by the standard rubber compound method (Table II) and the following values (Table III) for mechanical characteristics were obtained.

In Table III the cis-1, 4 content of expt no. 110 is lower than those of expt no. 123 and

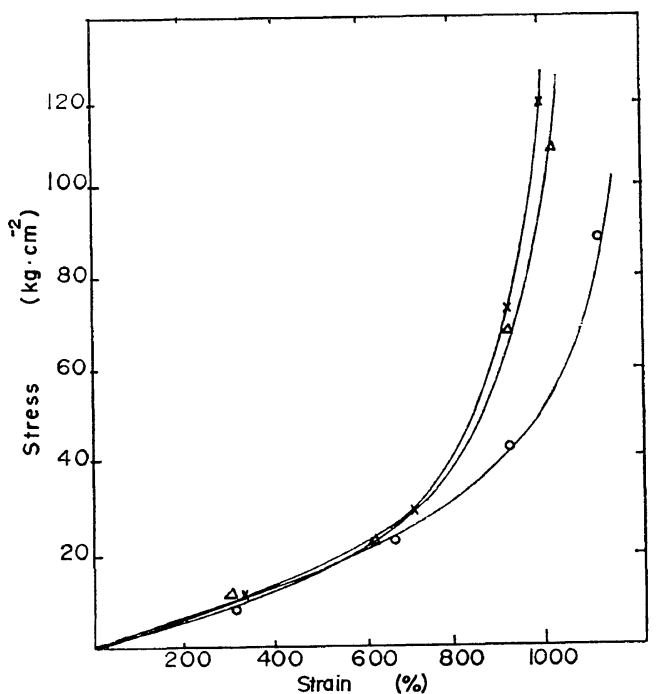

Figure 7. Stress-strain curve of vulcanized polyisoprene by the standard rubber compound method: $\bigcirc$, expt no. $110, \triangle$, expt no. 123 , $\times$, Cariflex-305; JIS-K 6031 No. 3 test piece; speed; $500 \mathrm{~mm} / \mathrm{min}$; at $20^{\circ} \mathrm{C} ; 60 \% \mathrm{H}$.

Cariflex-305 (Shell Chemical Company).

And this is one reason why the mechanical properties of expt no. 110 are inferior to those of expt no. 123 or Cariflex-305.

Figure 7 shows the stress-strain curve of vulcanized polyisoprene. In this figure the polymers obtained by the initiators are excellent in terms of tensile strength, modulus and elongation.

Acknowledgment. The authors wish to thank Associate Prof. I. Mita of the Institute of Space and Aeronautical Science, University of Tokyo for his interest in this investigation and Mr. M. Nagano of our Laboratory for the measurements of $\bar{M}_{n}$. 
Anionic Polymerization of Isoprene. I.

\section{REFERENCES}

1. D. J. Kelly and A. V. Tovolsky, J. Amer. Chem. Soc., 81, 1597 (1957).

2. S. Bywater and 'J. Worsford, J. Organometal. Chem., 7, 1; 8, 193 (1967).

3. M. Amagasa, et al., Abstract, SPSJ 17th Annual Meeting, Tokyo, May 1968, p 113.

4. J. Furukawa, et al., ibid., p 110.

5. M. Morton and J. Fetters, J. Polym. Sci., Part $A$, 2, 3311 (1964).

6. D. Margerison, D. M. Bishon, et al., Trans Faraday Soc., 64, 1872 (1968).

7. A. Gugot and J. Vialle, J. Polym. Sci., Part $A-1,5,2783$ (1967).

8. H. Morita and A. V. Tovolsky, J. Amer. Chem.
Soc., 79, 5853 (1957).

9. J. E. L. Roovers and S. Bywater, Macromolecules, 1, 328 (1968).

10. M. Morton and E. E. Bostick, J. Polym. Sci., Part A, 1, 475 (1963).

11. R. Milkovitch, et al., Japanese Patent S4023 798; S40-24 914; S40-24 915 (1965).

12. L. E. Forman, et al., U.S. Patent 3208988 (1965).

13. W. J. Torepuka, Japanese Patent, S40-15 830 (1965).

14. J. L. Binder and H. C. Ransaw, Anal. Chem., 29, 503 (1957).

15. M. Szwarc, M. Levy, and R. Milkovitch, $J$. Amer. Chem. Soc., 78, 2656 (1956). 